\title{
Treating acute bronchitis with a plant based dietary supplement: properties and efficacy assessment
}

\author{
Valery Poznyakovsky, Maria Shamova, Elena Vyalykh, Boisjoni Tokhiriyon, and \\ Valentina Lapina
}

Ural State University of Economics, March 8 Str., 62, 620144 Ekaterinburg, Russia

\begin{abstract}
In recent years, acute bronchitis has become one of the most widespread lung diseases. Therefore, there is a need for effective prevention and treatment procedures, with nutrition being one of the important factors to be taken into account. The present paper discusses the properties and efficacy of a new plant based dietary supplement that contains ingredients with synergistic properties and can be successfully applied to regulate metabolism when treating bronchopulmonary pathology. The plant based dietary supplement was administered to enhance the traditional treatment. One capsule was taken by the patients of the experimental group three times a day at breakfast, lunch and dinner for the period of 30 days. While the control group did not receive the plant based dietary supplement and undertook the standard form of treatment. By comparing all the data collected during the clinical trial, positive impact of the new plant based dietary supplement was observed, i.e. the exacerbation phase was shortened by two or three days, the period of the hospital treatment was reduced by five and a half days. Alongside the ease of the shortness of breath, improved lung function and lung vital capacity, were the increased volume of forced inhalation, the rallied mucociliary apparatus, and bronchial mucosal swelling reduction. The experimental group patients demonstrated both the increased tocopherol level and the growth in oxygen concentration. The positive changes were observed in metabolic process, i.e. lipid peroxidation, which in turn provides better exercise capacity. The data collected during the clinical trial is of huge importance and can help improve the life of the patients with acute bronchitis. Active ingredients of the new plant based dietary supplement influence both the chemistry of lipid peroxidation and antioxidant protection process against free-radical damage. This influence is particularly notable in the early stages of the disease. The clinical trial findings indicate that administering the new plant based dietary supplement as a part of a standard treatment is justified and effective. Moreover, the supplement can be successfully taken to prevent the acute bronchitis.
\end{abstract}




\section{Introduction}

There is a growing understanding that improved life quality and life expectancy hugely depend on proper prevention and the efficacy of complex treatment of common diseases, with acute bronchitis being one of the most widespread ones. According to the World Health Organisation, more than 15 per cent of all acute bronchitis cases develop complicated forms and become chronic.

Chronic bronchitis syndrome, which is the long-term inflammation of the bronchi, is among the most common complications in different age groups, accounting for up to 10-12 per cent of all diagnoses. In Russia, 26-29 per cent of lung diseases are followed by acute bronchitis. After being affected by acute bronchitis, 45 per cent of all middle-aged and elderly patients develop chronic inflammation [1-6].

Classifying acute bronchitis represents certain difficulty for a number of reasons. First, middle-aged patients usually have more than one disease (polymorbidity). Second, middleaged patients are quite often more inclined towards self-medicating at home, delaying seeking qualified help. Finally, middle-aged patients often continue with their usual routine totally ignoring the development of the disease.

All of the reasons above result in complications and chronic inflammation with the lung interstitium affected and, subsequently, followed by pulmonary fibrosis and the development of bronchiectasis.

Due to the reality of our modern, fast-pacing life with increasing air and water pollution and huge work overload, many patients do not undergo proper treatment of the disease and return to work prematurely. That means that, although, interstitial lung diseases have not been properly treated, patients rush to return to the usual routine and undertake the heavy load of a healthy person too early. Thus, when the disease is caused by a bacterial infection, even carefully administered antibiotic treatment does not contribute to proper interstitial tissue and bronchial mucosa repair.

Therefore, for the purposes of prevention, complex treatment and rehabilitation it is necessary to move towards functional foods that offer nutritional and metabolic support, i.e. plant based dietary supplements with particular qualities. The importance of nutrition has recently become the focus of attention in numerous national and international studies [717].

\section{The object of the study}

The object of the present study is to assess the efficacy and the functional properties of the new plant based dietary supplement when administered in complex therapy of acute bronchitis.

\section{Materials and methods}

Forty-one patients aged between 15 and 40 took part in the clinical trial. All of the patients were diagnosed with acute bronchitis and were admitted for in-hospital treatment, with 13 of the patients suffering from chronic obstructive pulmonary disease.

Almost 80 per cent of the patients were older that twenty-one, but the patients were not divided into younger and older ones as sample group size is crucial for clinical research. To ensure the correctness of the diagnoses, the necessary clinical data was obtained, including mandatory laboratory tests, two view chest X-rays as well as bronchoscopy. 
Capillary blood oxygen saturation ( $\mathrm{SpO} 2)$ was measured from skin using ABL-50 oxymonitor manufactured by RADIOMETER, Denmark. The data collected was then compared to the data received from 20 healthy volunteers aged from 25 to 40 .

The patients of the control group were administered the standard treatment, while the patients from the experimental group were prescribed a plant based dietary supplement, one capsule of which was taken three times a day at breakfast, lunch and dinner for the period of 30 days. The composition of the plant based dietary supplement includes ingredients that have a unidirectional, synergistic effect and enhance metabolism, i.e. caprylic triglycerides - 479.4; chaga extract - 35; pro-vitamin coniferous concentrate - 25 (polyprenols - 5); moomiyo (Shilajit) extract - 35; Ginseng extract, 1\% - 10 (eleutheroside B and E - 0.1); royal jelly - 5; Schisandra extract, $2 \%-5$ (schizandrin - 0.1) per one capsule. The polyprenols, being the main active ingredient, are obtained from Siberian Fir greens through a multiphase extraction process and represent purified active substance.

Table 1 shows the distribution of patients from both groups by gender and age. The data in Table 2 indicates the distribution by the severity of the disease. It should be noted, that there is no notable difference between moderate and severe cases. Table 3 includes the data on patients' distribution by the post-bronchodilatory response.

Table 1. The distribution of the patients by gender and age.

\begin{tabular}{|c|c|c|c|c|}
\hline Groups & $\begin{array}{c}\text { Number of } \\
\text { patients }\end{array}$ & Males & Females & Age \\
\hline Control & 20 & $12(84.6 \%)$ & $8(15.4 \%)$ & $36.9 \pm 1.3$ \\
\hline Experimental & 21 & $15(86.2 \%)$ & $6(13.8 \%)$ & $38.1 \pm 1.3$ \\
\hline Total & 41 & 27 & 14 & $37.4 \pm 0.5$ \\
\hline
\end{tabular}

Table 2. The distribution of the patients by the severity of the disease.

\begin{tabular}{|c|c|c|c|c|}
\hline Severity & $\begin{array}{c}\text { Forced expiratory } \\
\text { volume (\% normal } \\
\text { value) }\end{array}$ & Total & $\begin{array}{c}\text { Control } \\
\text { group }\end{array}$ & $\begin{array}{c}\text { Experimental } \\
\text { group }\end{array}$ \\
\hline $\mathbf{2}$ & $51-68 \%$ & 45 & 13 & 17 \\
\hline $\mathbf{3}$ & $<50 \%$ & 39 & 14 & 13 \\
\hline \multicolumn{2}{|c|}{ Total } & 84 & 27 & 30 \\
\hline
\end{tabular}

Table 3. The distribution of the patients by the post-bronchodilatory response.

\begin{tabular}{|c|c|c|c|c|}
\hline Group & $\begin{array}{c}\text { Expected } \\
\text { Forced } \\
\text { expiratory } \\
\text { volume }\end{array}$ & $\begin{array}{c}\text { Factual Forced } \\
\text { expiratory } \\
\text { volume }\end{array}$ & $\begin{array}{c}\text { Forced expiratory } \\
\text { volume at the start } \\
\text { of the treatment, } \\
\text { (\% normal value })\end{array}$ & $\begin{array}{c}\text { Forced expiratory volume } \\
\text { after salbutamol, } \mathbf{\%} \\
\text { normal value) }\end{array}$ \\
\hline Control & $3.39 \pm 0.04$ & $1.84 \pm 0.04$ & $54.6 \pm 1.2$ & $12.4 \pm 0.3$ \\
\hline Experimental & $3.42 \pm 0.05$ & $1.31 \pm 0.03$ & $53.3 \pm 1.09$ & $12.5 \pm 0.31$ \\
\hline
\end{tabular}

\section{Results and Discussion}

The findings of the clinical trial illustrated the patients' response to salbutamol, and the post-bronchodilatory response proved the sample to be representative. The forty-one 
participants were carefully observed during the acute phase of the disease, with all the necessary laboratory tests taken and all the signs and symptoms registered.

All the changes in clinical manifestations that occurred while treatment were analysed. During the acute exacerbation phase, when the patients were admitted to the hospital, all complaints were recorded. The patients experienced shortness of breath, high fever, paroxysmal cough, fatigue, mild headache, sweating, which were more intense in the morning hours. The patients were admitted to the hospital with cough and mucopurulent sputum. The lugs of the patients with moderate disease severity produced $30-50 \mathrm{ml}$ of the sputum per day, while the patients with severe acute bronchitis produced up to $100 \mathrm{ml}$ and more per day, while their sputum turning purulent. All of the patients experienced lingering coughing and suffered from the shortness of breath, when exposed to cold air and strong odours. Moreover, most patients endured excessive sweating in the morning hours and at night in the upper part of their shoulder girdle. Two thirds of the patients had subfebrile temperature.

As a result of clinical examination of the patients, the following medical conditions were registered: 30 per cent of the patients used the assessor muscles while coughing and experienced swelling of the neck veins. The respiratory rate of two thirds of the patients was higher than 24 breaths per minute, with all the patients having sinus tachycardia. 51 per cent of the examined patients registered barrel chest. Moderate cyanosis of mucous membranes and skin was found in 12 per cent of cases and 15 patients has swollen shins.

When chest percussion was performed, the percussion sound produced in 53 per cent of the cases resembled a band-box sound. The examination of most of the patients revealed that the lungs showed downward displacement and the mobility was limited. All patients produced whistling, scattered, and dry rales above the surface of the lungs when breathing, with rales intensifying during inhaling. When examining all patients, prolonged expiration was registered.

73 per cent of the patients revealed muffled heart sounds; the accent of the second tone over the pulmonary artery was detected in 77 per cent of the cases.

The X-ray examination indicated that in 17 per cent of the cases the roots of the lungs were affected. The patients with repeated bouts of bronchitis had symptoms of pneumosclerosis (63 per cent of the patients) or symptoms of emphysema in 30 per cent of the cases.

During bronchoscopy all patients showed signs of diffuse endobronchitis with different degrees of severity. Two thirds of the patients experienced bronchial mucosal bleeding.

The results of biochemical and general clinical blood tests were typical to the test results of patients with acute bronchitis. The blood test results of the patients of both, the control and the experimental groups, indicated leukocytosis (12-14 x $109 / 1)$ in 25 and 26 per cent of cases, respectively. The white blood cell count was in the range of 8.5-11 x 109 / 1, with 6-10 per cent of leukocytes in the form of stabs. Erythrocyte Sedimentation Rate was high in all cases.

When the patients were admitted to the hospital, the concentration of sialic acids, seromucoids and the level of C-Reactive protein were used as the markers of the acute phase, with all the patients demonstrating higher levels.

The administration of the plant based dietary supplement resulted in the ease of the clinical symptoms at the exacerbation of the acute bronchitis. In the experimental group, the ease of the clinical symptoms was recorded earlier than that in the control group. The frequency and severity of the coughing fits decreased two-three days earlier, the mucus secretion lowered and its daily production decreased by $20-30$ per cent compared to the control group data.

Having taken the dietary supplement for 5-7 days, the patients of the experimental group were routinely examined, and significant decrease in wheezing was recorded, while 
the patients from the control group demonstrated no such changes. On the whole, the administration of the dietary supplement resulted in the ease of the clinical symptoms two or three days earlier; therefore shortening the length of overall hospital stay. The average length of stay for the patients from the experimental group was five and a half days shorter than that of the control group, and lasted for $19.7 \pm 1.4$ days, which is very important for economic reasons as well as for the patients.

At the examinations taken on the 10th-14th days of therapy, shortness of breath was recorded in 50 per cent of the cases with the patients undertaking moderate physical activity, and with vigorous physical activity all the patients experienced shortness of breath. By the end of the treatment, this indicator was recorded in 39 per cent of the cases, and it still remained after the treatment in 26 per cent of the cases.

The positive dynamics of the speed and volumetric indicators of lung ventilation were recorded. By the end of the treatment period, an increase in the vital lung capacity was documented, which was 7.5 per cent higher compared with the data from the control group.

The patients from the experimental group demonstrated a 31.9 per cent increase in the forced inspiratory volume, when compared with the data recorded on the admission day and the data received on the 10th-14th days of treatment, and a 48 per cent increase at the end of the treatment period.

The patients from the control group demonstrated a 5.2 per cent and a 17.3 per cent increase, respectively. Thus, the patients, who underwent complex treatment with the dietary supplement, demonstrated an increase in the forced inspiratory volume in the first two weeks of the treatment period and remained the same level 30 days after the treatment. The patients from the control group did not have the same results.

The positive changes in the forced inspiratory volume can be explained by the antiinflammatory effect of the tested dietary supplement and proved by the data on lipid peroxidation and the activity of the antioxidant system. Ten to fourteen days of the complex therapy helped reduce the bronchial swelling and increase the forced inspiratory volume with the clearance of the mucociliary apparatus.

The oxygen saturation index was also calculated and studied when the patients were first admitted to the hospital and after two weeks of treatment. The oxygen saturation index calculated on the admission was similar for the patients from both groups. After two weeks of complex therapy with the dietary supplement, the oxygen saturation index of the patients from the experimental group increased by 4 per cent, while the patients from the control group experienced an increase of 1.7 per cent. The difference in data remained after the end of the treatment.

The oxygen saturation index increase was due to the ease of inflammatory processes in the bronchial tree and the marked improvement in ventilation-perfusion function. Lipid peroxidation and the activity of the antioxidant system of the patients from the experimental group were carefully studied and the positive changes are presented in Table 4.

Table 4. Lipid peroxidation and the activity of the antioxidant system.

\begin{tabular}{|c|c|c|c|c|c|}
\hline Indicator & Healthy people & Patients & On admission & $\begin{array}{c}\text { The 10th-14th day } \\
\text { of treatment }\end{array}$ & On discharge \\
\hline $\begin{array}{c}\text { Malondialdehyde } \\
\text { (nmol / mg) } \\
\text { Lipids) }\end{array}$ & $0.99 \pm 0.048$ & $\begin{array}{c}\text { The experimental } \\
\text { group }\end{array}$ & $3.14 \pm 0.059$ & $1.36 \pm 0.052$ & $0.88 \pm 0.047$ \\
\cline { 3 - 6 } & The control group & $2.69 \pm 0.055$ & $2.66 \pm 0.056$ & $2.4 \pm 0.052$ \\
\hline $\begin{array}{c}\text { Tocopherol } \\
(\boldsymbol{\mu g} / \mathbf{m l})\end{array}$ & $9.0 \pm 0.33$ & $\begin{array}{c}\text { The experimental } \\
\text { group }\end{array}$ & $4.91 \pm 0.42$ & $11.35 \pm 0.38$ & $2.55 \pm 0.32$ \\
\cline { 3 - 6 } & The control group & $5.46 \pm 0.40$ & $5.03 \pm 0.39$ & $5.57 \pm 0.39$ \\
\hline
\end{tabular}


The use of the dietary supplement helped decrease malondialdehyde level and the difference in MDA level was more noticeable by the end of the clinical trial.

The fact that the patients from the experimental group demonstrated positive changes in exercise tolerance can be explained by the improvement in ventilation-perfusion function, oxygen saturation and pulmonary hemodynamics (Table 5).

Therefore, the benefits of the plant based dietary supplement use in complex therapy of patients with acute bronchitis have been clinically proved. It should be noted that the concentration of Vitamin $\mathrm{E}$ in blood serum more than doubled due to the sufficient intake of tocopherol with the dietary supplement.

Table 5. The use of the dietary supplement and exercise tolerance.

\begin{tabular}{|c|c|c|c|c|}
\hline Indicator & $\begin{array}{c}\text { Healthy } \\
\text { people }\end{array}$ & Patients & On discharge & $\begin{array}{c}\text { 30 days after the } \\
\text { discharge }\end{array}$ \\
\hline $\begin{array}{c}\text { Work performed, } \\
\text { intensity, } \\
\text { kgm / kg body weight / } \\
\text { min }\end{array}$ & $9.62 \pm 0.10$ & $\begin{array}{c}\text { The experimental } \\
\text { group }\end{array}$ & $7.5 \pm 0.15^{* *}$ & $6.5 \pm 0.19^{* *}$ \\
\cline { 3 - 5 } & & The control group & $5.3 \pm 0.11^{*}$ & $5.5 \pm 0.18^{*}$ \\
\hline \multirow{2}{*}{$\begin{array}{c}\text { Work performed, } \\
\text { volume, kgm }\end{array}$} & $6194 \pm 672$ & $\begin{array}{c}\text { The experimental } \\
\text { group }\end{array}$ & $53895 \pm 821$ & $5053 \pm 768$ \\
\cline { 3 - 5 } & & The control group & $3382 \pm 683^{*}$ & $3452 \pm 638^{*}$ \\
\hline
\end{tabular}

* - compared to healthy people; ** - compared to the control group patients.

The standard therapy combined with the use of plant based dietary supplement resulted in positive improvement of the balance of lipid peroxidation and the activity of the antioxidant system. The data collected during the clinical trial allows us to prove the efficacy of plant based dietary supplement in the complex therapy of acute bronchitis.

This diet therapy is effective as the ingredients of the dietary supplement, i.e humic acid, polyprenols, chaga, help reduce lipid peroxidation, improve antioxidant status, and thus, lessen the risk of complications.

The active ingredients of the plant based dietary supplement show considerable antiradical activity, thus, when taken during the acute phase, they contribute to a fast and remarkable activation of nonspecific defence at the cellular and extracellular levels.

Thirty days after the complex therapy, there was an increase in lipid peroxidation and the decrease in antioxidant status, which means that there is a need to administer longer dietary supplement intake in order to prevent disease complications.

\section{Conclusion}

Acute bronchitis is one of the common conditions why patients seek medical care. Acute bronchitis is characterised by the increase in lipid peroxidation and the decrease in antioxidant status, which means that there is a need to prevent disease complications. The clinical manifestations of the disease are characterized by a high intensity of lipid oxidation.

2. The use of the plant based dietary supplement with antioxidant properties is clinically effective during an acute exacerbation of bronchitis. The earlier the dietary supplement is added to the complex therapy, the better and faster positive changes become. The feasibility 
of the long-term administration of the dietary supplement is explained by the need to prevent the development of lipid peroxidation process, and to maintain antioxidant status.

3. It has been concluded that for elderly patients, it is highly desirable to increase the intake of the plant based dietary supplement and take it up to 4 times a day, as the data collected during the clinical trial indicates that in case of older patients the positive changes after taking the dietary supplement are less evident, when compared to the data collected on younger patients.

\section{References}

1. N. G. Zhevachevsky, The art of being healthy: a guide for doctors and consultants, 508 (Advertising and publishing company, Novosibirsk, 2016)

2. N.V. Trushenko, A.S. Belevskiy, Practical pulmonology, 2 (2017)

3. V.M. Poznyakovskiy, O.V. Chugunova, M.YU Tamova, 143 (RF: INFRA-M, Moscow, 2017)

4. N.F. Gerasimenko, V.M. Poznyakovskiy, N.G. Chelnakova, Human. Sport. Medicine, 1 (2017)

5. V. V. Ttrihina, V. B. Spirichev, V. Z. Koltun, A. N. Avstrievskih, Foods and Raw Materials, 3 (2015)

6. G. Latkovskis, V. Saripo, E. Sokolova, D. Upite, VanagaI, U. Kletnieks, A. Erglis, ScinceDirect, 52 (2016)

7. H. Sagami, E. Swiezewska, Y. Shidoji. Bioscience, Biotechnology and Biochemistry, 82 (2018)

8. E.I. Tsoi, E.V. Vyshlov, V.B. Trusov, The Siberian Medical Journal, 33 (2018)

9. M. Khodanovich, A. Pishchelko, V. Glazacheva, Plant Pan E. Phytotherapy Research, 33 (2019)

10. B. Tokhiriyon, V. M. Poznyakovsky, IOP Conference Series: Earth and Environmental Science, 315 (IOP Publishing, United Kingdom, 2019)

11. B. Tokhiriyon, E. V. Vyalyh, V.M. Poznyakovsky, International Scientific and Practical Conference 'Digital agriculture - development strategy', 167 (International Scientific and Practical, Ajman, 2019)

12. B. Tokhiriyon, V. M. Poznyakovsky, S. Andrievskikh, Carpathian journal of food science and technology, 12 (2020)

13. G.F. Deng, S. Li, F. Li, S. Wu, H.B. Li and X.R. Xu, Phytochemicals: occurrence in nature, health effects and antioxidant properties, 2 (2013)

14. N. Lund, M.L. Westergaard, M. Barloese, Cephalalgia, 34 (2014)

15. V. P. Georgievsky, N. F. Komisarenko and S. E. Dmitruk, Biologically active substances of medicinal plants, 333 (Science, Siberian branch, Novosibirsk, 1990)

16. N. F. Santos-Sanchez, R. Salas-Coronado, Acta scientiarum polonorum-technologia alimentaria, 16 (2017)

17. L. Krupytska, L. Kaprelyants, L. Trufkati, Journal of food science and technologyukraine, 12 (2018) 